This PDF is a selection from an out-of-print volume from the National Bureau of Economic Research

Volume Title: Marriage, Family, Human Capital, and Fertility

Volume Author/Editor: Theodore W. Schultz, editor

Volume Publisher: Journal of Political Economy 82(2), Part II, April 1974

Volume URL: http://www.nber.org/books/schu74-2

Publication Date: 1974

Chapter Title: Effects of Child-Care Programs on Women's Work Effort

Chapter Author: James J. Heckman

Chapter URL: http://www.nber.org/chapters/c3687

Chapter pages in book: (p. 136 - 169) 


\section{Effects of Child-Care Programs on Women's Work Effort}

\section{James J. Heckman}

Columbia University and National Bureau of Economic Research

In recent years, Congress has considered a variety of work-subsidy programs designed to encourage work among welfare recipients. Many of these programs would subsidize individuals only if they work some minimum number of hours. Commonly used techniques cannot give direct answers to relevant policy questions since a tied offer is involved, and hence the offer cannot be treated as a simple wage change. The essence of the problem involves utility comparisons between two or more discrete alternatives. Such comparisons inherently require information about consumer preferences in a way not easily obtained from ordinary labor-supply functions.

To make such comparisons, I present a method for directly estimating consumer indifference surfaces between money income and nonmarket time. Once these surfaces are determined, they can be used to compare a variety of alternative programs to investigate whether or not there is scope for Pareto-optimal redistribution of income transfers and time, improving the general level of welfare of the community at large without reducing the welfare of individuals receiving income transfers. Knowledge of these indifference surfaces allows us to estimate reservation wages to estimate the value of nonworking-women's time (Gronau 1973), laborforce participation functions, hours-of-work functions, and welfare losses due to income tax programs (Harberger 1964). I demonstrate that direct estimation of indifference surfaces allows us, at least in principle, to relax

This research was sponsored by National Science Foundation and Office of Economic Opportunity grants to the National Bureau of Economic Research. I gratefully acknowledge Ralph Shnelvar's skilled programming assistance. Orley Ashenfelter, Charles Betsey, Jacob Mincer, Marc Nerlove, Mel Reder, James Smith, Finis Welch, and Robert Willis provided useful comments. I thank Elisabeth Parshley for her assistance. I retain full responsibility for all errors in the paper. This paper has not undergone NBER staff review and is not an official publication of NBER, NSF, or OEO. 
the conventional assumption that the wage rate is independent of hours of work. The separation of preferences and constraints allows us to estimate labor-supply functions for individuals affected by welfare systems and progressive income taxation.

The methodology presented here is similar in spirit to the pioneering work of Wald (1940). In his neglected paper, Wald suggested that information from different price situations can determine a family of indifference curves up to a second-order approximation. In this paper, I depart from Wald's methodology and suggest a plausible estimable specification for the marginal rate of substitution function between goods and leisure, the parameters of which are estimated by maximum-likelihood methods.

The particular focus in this paper is on the effect of work-related childcare programs. However, the methodology is more general and may be applied to a variety of work-subsidy programs.

\section{An Anatomy of Proposals for Child-Care Programs}

Proposals designed to relieve work-related child-care expenses have received the most attention. The Nixon administration has promoted several measures of this type. In 1971, an administration bill (HR 1) was introduced as "workfare" legislation designed to vacate welfare rolls by providing child care to working women. In 1972, tax laws were modified to give generous deductions for work-related child-care expenses if a woman worked 30 hours a week or more. Since some work requirement seems likely in any future legislation, I confine my analysis to such programs.

If a child-care program gives a woman with a child an hourly supplement for each hour she works, and she is free to spend it on any childcare source, the supplement is equivalent to a wage change of equal magnitude on both her hours of work and her decision to work. Given reliable estimates of work participation and hours-of-work functions, it is straightforward to make projections of the labor-supply effects of alternative programs.

If a cash grant or tax rebate is given to working women with children, it is no longer possible to proceed so simply. Given an agreed minimum number of hours which defines the condition of working, the wage rate for hours worked in excess of the minimum is not affected by such offers although the wage rate for hours worked below the minimum is increased. For currently working women who work in excess of the minimum, there are only income effects. If nonmarket time is a normal good, such offers will diminish their hours of work. Women working below the minimum will either increase their work to the minimum number of hours or will be unaffected by the program. For nonworking women market work is 


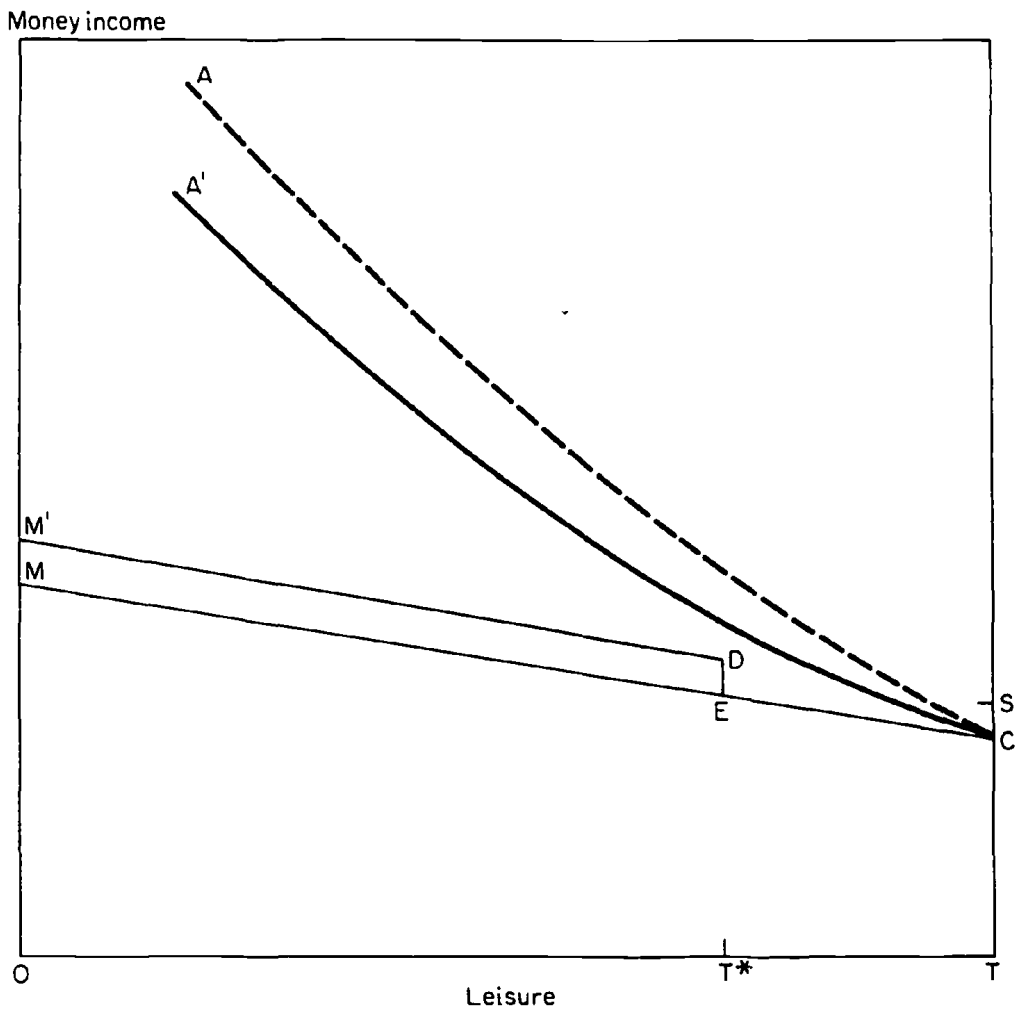

Fig. 1

more attractive, and some portion of them will be expected to commence working.

Knowledge of the reservation wage (i.e., the minimum wage that a woman will accept to go to work) does not enable us to form estimates of program labor-supply effects. To see this, consider the familiar laborleisure diagram reproduced in figure 1.

Since we only consider wage changes, we may compress all other goods into money income and construct an indifference curve between money income and nonmarket time or leisure. That there are many uses for nonmarket time is inessential to the argument as long as time is freely transferable among its uses.

Suppose that a woman (or family unit) can enjoy $T C$ units of money consumption if she does not work and that her wage rate is independent of her hours of work so that the market opportunity line is $C M$. The individual (or family) is on indifference curve $A C$ if the woman does not work. As drawn, the slope of the indifference curve at zero hours of work (i.e., the reservation wage) exceeds the offered wage rate (given by the slope of $M C$ ) so that the woman does not work. Suppose the government 
gives the woman supplement $S C$ but requires her to work at least $T^{*} T$ hours to qualify as working. As the figure is drawn, the woman will not take the offer. Her effective budget constraint becomes $M^{\prime} D E C$, and the government subsidy does not improve her (or her family's) welfare. Raising the size of the subsidy or reducing the extent of required effort may reverse this conclusion.

In practice, tax rebates may be more complicated. If the "work requirement" becomes a minimum-earnings requirement which must be attained to be able to deduct child-care expenses, $T^{*}$ will depend on the wage rate, shifting to the right for higher-wage women and making the program differentially more attractive to them, thus working in an opposite direction to the Nixon "workfare" proposals, ceteris paribus. Furthermore, since high-income families are more likely to itemize deductions, tax rebates for child care will tend to favor such families, although surely in the presence of these rebates more low-income families would find it profitable to itemize their deductions.

Suppose that the government operates on the supply side of the market by reducing the price per unit quality of work-related child care. ${ }^{1}$ Remembering that the composite commodity theorem (Hicks 1946) allows us to aggregate all goods whose relative prices do not change into money income, a reduction in the price of work-related child care is equivalent to a shift in the indifference map of figure 1 from $A C$ to $A^{\prime} C .^{2}$ With lower price per unit quality, consumers can attain the same basket of market goods (including the quality of their work-related child care) with lower money income. Hence, $A^{\prime} C$ lies below $A C$ but the two curves meet at $C$ because at this point no work is undertaken and the expenditure on work-related child care is zero. Its price is irrelevant to the height of the curve at this point but a reduction in the price of work-related child care reduces the slope of the curve at $C$ (i.e., the reservation wage). ${ }^{3}$ time.

1 I ignore the practical difficulties in enforcing child-care provision solely for working

2 This analysis assumes that individuals are free to choose the quality per unit hour of their child care. If for some reason the quality per hour is not an object of choice, the appropriate wage for labor-supply decisions is the wage net of hourly child-care costs. Only in this case can child care be treated as a cost of work. Since fixity here, as elsewhere, is unreasonable to impose a priori, I do not pursue this approach. However, I mention this case because it is tempting to treat child-care expense as a cost. Throughout this paper I assume that quality can be varied. That only rarely do children go unsupervised when a mother works is a statement about consumer preferences and not one about the need to consume a minimum amount of child-care quality. Using these expenditures as exogenous variables in regression analysis of labor supply when in fact they are an object of choice would bias the resulting labor-supply estimates.

${ }^{3}$ The proof of these propositions is relatively straightforward and is deleted for the sake of brevity. Note that, in the text, I only argue that the reservation wage for $A C$ exceeds that for $A^{\prime} C$. In general, the slope of $A C$ might not exceed the slope of $A^{\prime} C$ for any arbitrary hours-of-work position unless total expenditure on child-care quality rises with increasing hours of work along any iso-utility curve or, what amounts to an equivalent proposition, that work and quality per hour of purchased child care are HicksAllen substitutes. 
Since the reservation wage has decreased more women will now work. If the price per unit quality is reduced for all child care, whether or not it is work related, the two curves no longer intersect at $C$, but if the expenditure on nonwork-related child care is small the assumption of intersection may remain plausible.

An important question for policy purposes is whether women receiving grants should be free to spend those grants on any form of child care service. In President Nixon's veto message (December 10, 1971) an unrestricted voucher scheme was proposed. However, the Secretary of the Department of Health, Education, and Welfare testified that the administration favored monitoring voucher use so that only "authorized" quality sources could be used for expenditure of child-care vouchers (March 27, 1972). ${ }^{4}$ This distinction is quite important. It is well known that over 80 percent of working women with small children do not use formal day-care services (Low and Spindler 1968; Ruderman 1968). Since families are free to resort to the market, the implication of this fact is that the price per unit quality of these informal sources is less than that available in the market. If individuals are given cash grants or wage supplements and simultaneously are allowed to spend them only in the formal market, two offsetting effects are at work for women who have informal child-care sources available. On the one hand, a wage or income subsidy for working raises the attractiveness of work effort. On the other hand, the price change shifts the indifference curves (e.g., from $A^{\prime} C$ to $A C$ in figure 1) and tends to offset work incentives. A currently working woman who uses informal arrangements may either remain unaffected by the program or switch into the "formal" program. For policy purposes, it is important in assessing revenue costs to know how many will, in fact, switch over to formal sources.

\section{Estimating Indifference Curves}

If we knew a consumer's system of indifference curves and how this system shifts in response to variations in the price of child care, we could answer the policy questions raised in Section I. Since ordinary laborsupply functions are derived from indifference curves and their parameters may be used to estimate such curves, why bother to directly estimate them? My answer comes in four parts.

The first is that direct estimates of indifference curves allow us to derive the parameters of both hours-of-work and decision-to-work functions from a common set of parameters, enabling us to present a unified framework in which to interpret these two aspects of work behavior as well as giving an economy in parameters to be estimated. Second, by estimating

\footnotetext{
${ }^{4}$ Again, I abstract from the very real problem of enforcing quality standards.
} 
indifference curves we can combine observations on all women, whether or not they work, and can avoid both the extrapolation error involved in using observations on working women to estimate the indifference surfaces appropriate to all women and the censored-sample problem that arises from estimating labor-supply parameters on a subsample of working women. A sample is censored when data are missing for some observations for reasons related to the model in question. Thus, for example, when a woman does not work we do not know what wage she would earn were she to work. The reason she does not work is that her reservation wage (i.e., the slope of the indifference curve at the zero hours-of-work position) exceeds the (unknown) available market wage. Estimates of wage functions and labor-supply functions based on subsamples of working women lead to biased parameter estimates (see Aigner 1971; Heckman 1972; Gronau 1973). Third, by estimating indifference surfaces we can directly estimate reservation wages and can use these estimates as Gronau (1973) has done to estimate the value nonworking women place on their time. These estimates provide a "reasonableness" criterion with which to judge laborsupply estimates apart from the usual sign restrictions on income and substitution effects. We can further judge the desirability of any laborsupply specification by asking what reservation wage the functional form implies.

A fourth reason for directly estimating indifference curves is that the procedure allows for the separation of preferences from constraints. The ability to make this separation is less important if we are willing to make the conventional assumption that wage rates are independent of hours of work (e.g., Kosters 1966) but becomes quite important when we acknowledge the existence of progressive taxation, welfare regulations, and time and money costs of work. Thus, for example, even if the pretax wage is independent of hours of work, progressive income taxes create breaks in the budget constraint, since tax rates are set on income intervals and change discontinuously at boundaries. While it may be reasonable to assume smoothness in tastes, the resulting labor-supply functions may be quite intractable either to specify or to estimate (see Wales 1973). My procedure supplies a natural solution to this problem, and it admits of ready generalization to data from welfare populations which face similarly distorted budget lines.

\section{A. Estimable Indifference Curves}

Any indifference curve may be characterized as a locus of points or as an envelope of tangents. For my purposes, the latter characterization is more convenient. Given any initial consumption position, the reservation wage is the slope of the indifference curve at zero hours of work. If leisure is a normal good, higher initial endowments lead to higher reservation 
wages (Hicks 1946, pp. 28-29). We have seen that higher prices for childcare quality lead to higher reservation wages if a woman uses some child care when she works.

We may write the marginal rate of substitution function (or slope of the indifference curve) at a given level of prework income $Y$ as

$$
m=m\left(p_{q}, Y, h\right),
$$

where we ignore variations in the price of other goods and where $h$ is hours of work and $p_{q}$ is the price per unit quality of child care. A consumer possesses a family of indifference curves indexed by level indicator $Y$, the no-work level of money income or consumption. We know that $\partial m / \partial Y>0$ (normality of nonmarket time) and that $\partial m / \partial p_{q}>0$ at the zero hoursof-work position. Moreover, it is plausible that this inequality remains valid for all values of $h{ }^{5}$ From diminishing marginal rate of substitution between goods and time we know that $\partial m / \partial h>0$.

If a consumer faces a parametric wage $W$, at initial income position $Y$, she works if $W>m\left(p_{q}, Y, 0\right)$. If this inequality applies, the equilibrium position is characterized by

$$
W=m\left(p_{q}, Y^{*}, h^{*}\right),
$$

where $Y^{*}$ is a level index appropriate to the equilibrium indifference curve and is nothing more than the amount of money income that would make the consumer indifferent to a choice between working $h^{*}$ hours at wage rate $W$ to gain total resources $W h^{*}+Y$ or not working and receiving income $Y^{*}$. As things stand, without knowledge of $Y^{*}$, we cannot deduce the equilibrium relationship between $W$ and $h$. However, given $Y^{*}$, we know that equilibrium also requires that

$$
W h^{*}+Y=\int_{0}^{h^{*}} m\left(p_{q}, Y^{*}, h\right) d h+Y^{*} .
$$

This equilibrium condition states that we may imagine moving the consumer to her final equilibrium position in one of two ways: giving her a flat hourly wage rate of $W$ or giving her payment $Y^{*}-Y$ to be added to her initial resource endowment $Y$ and compensating her by amount

$$
\int_{0}^{h^{*}} m\left(p_{q}, Y^{*}, h\right) d h,
$$

which is nothing more than the area under her (real) income-compensated supply curve for labor. Given $W, h, Y$, and $p_{q}$ we may solve out for $Y^{*}$.

${ }^{3}$ Strictly speaking, it is possible that beyond certain values of $h$ this expression becomes negative, but for this to occur would require decreasing quality expenditure on child care as hours of work increase, holding the consumer at the same level of utility (see n. 3 above). 
From equation (2), if $m$ is monotonic in $Y^{*}$ we may solve for $Y^{*}$ as a function of $p_{q}, W$, and $h: Y^{*}=g\left(p_{q}, W, h\right)$; using this value in equation (3), we implicitly define the labor-supply function by

$$
W h+Y=\int_{0}^{h} m\left[p_{q}, g\left(p_{q}, W, h\right), h\right] d h+g\left(p_{q}, W, h\right) .
$$

\section{B. A Particular Functional Form for $m$}

A wide variety of functional forms may be used to specify $m .^{6}$ One plausible specification, arrived at after considerable empirical experimentation, is to write

$$
\ln m=\alpha_{0}+\alpha_{1} \ln p_{q}+\alpha_{2} Y+\alpha_{3} h+\alpha_{4} Z+u
$$

where, as before, $p_{q}$ is the price per unit quality of child care, $Y$ is the prework level of income, $h$ is hours of work, and $Z$ is a vector of constraints to be discussed more fully below. A random variable designated " $u$," with zero mean and variance $\sigma_{u}^{2}$, reflects variation in preferences for work among individuals. The previous analysis leads me to the prediction that $\alpha_{2}>0$ (normality of leisure) and $\alpha_{3}>0$ (diminishing marginal rate of substitution between goods and leisure) and to the presumption that $\alpha_{1}>0$.

Manipulation along the lines discussed in section A shows that the resulting labor-supply function is implicitly defined by

$$
\begin{aligned}
u= & \ln W-\alpha_{0}-\alpha_{1} P_{q}-\alpha_{3} h-\alpha_{4} Z \\
& -\alpha_{2}\left[W h+Y-\frac{W}{\alpha_{3}}\left(1-e^{-\alpha_{3} h}\right)\right] .
\end{aligned}
$$

This labor-supply curve can become backward bending beyond a certain value for hours worked. ${ }^{7}$

This particular functional form is offered as a starting point. If it is grossly inconsistent with the data, either $\alpha_{2}$ or $\alpha_{3}$ will be negative, and the implied reservation wages, predicted from estimates of equation (4), will be unreasonable.

${ }^{6}$ One method is to let the data determine the functional form, in the manner of Box and Tidewell (1962) and Box and Cox (1964). I did not pursue that approach in this paper.

${ }^{7}$ Straightforward differentiation of eq. (5) shows that $\partial h / \partial W=\left\{(1 / W)-\alpha_{2}[h-\right.$ $\left.\left.\left(1 / \alpha_{3}\right)\left(1-e^{-a_{3} h}\right)\right]\right\} /\left[\alpha_{2} W\left(1-e^{-a_{3} h}\right)+\alpha_{3}\right]$. Clearly, $1 / W$ is nonnegative; the denominator is positive, as is the first expression in brackets. To see why the latter assertion is true, note that when $h=0$ the first bracketed expression is zero and that the partial of that bracketed expression with respect to $h$ is $\left(1-e^{-\alpha_{3} h}\right)$, which is clearly nonnegative since $\alpha_{3}$ is positive and $h>0$. Thus, it is possible, for suitably large values of $h$, for $\partial h / \partial W$ to become negative. 


\section{The Empirical Specification}

To estimate the relevant parameters, we must specify the time dimension of the decision period and the vector of constraints $(Z)$ which affect the marginal rate of substitution between goods and leisure. For the purposes of this paper, I use hours worked in a given year. In my judgment, this dimension is the appropriate one for analyzing the labor-supply behavior of women with children-the target population for child-care programssince we are interested in knowing how they will respond to programs at the age when they have their children. I simplify the analysis by assuming that variations in the wife's labor supply do not affect the husband's earnings. $^{8}$

We may follow a well-established tradition in the literature and postulate a one-period static model, or we may imagine the individual woman (or household) maximizing her lifetime utility function at each age of her life, subject to the constraints reflecting past decisions and chance events. The traditional static model may easily be shown to be a special case of a more general life-cycle model.

To simplify exposition and maintain comparability with previous studies in labor supply, I assume a one-period framework. After presenting the essential features of my procedure under this assumption, I then show how to incorporate more general intertemporal considerations.

In specifying the list of variables $(Z)$ that would plausibly affect the marginal rate of substitution between goods and leisure, the presence of children of different ages and the price per quality unit of child care are the most obvious candidates.

Since children require time and effort, it is likely that the presence of children, especially young children, makes market work less attractive. ${ }^{9}$ If a mother works and values her child's environment during her working hours, she will make child-care arrangements. The effect of children on the indifference system allows us to estimate what compensation is necessary to induce the woman to work and how the presence of children affects the hours worked by women.

An important empirical fact is that most working women with small children do not pay for their child care, or if they do pay they use informal sources and pay less than women using formal sources. Some economists have interpreted this fact as evidence of failure in the child-

${ }^{8}$ This assumption is widely used (see Gronau 1973; Bowen and Finegan 1969), but it is clearly open to the criticism that the family labor supply is jointly determined. This assumption is equivalent to fixing the husband's nonmarket time institutionally or excluding it altogether from household preferences.

9 For example, if children require at least some minimum amount of the mother's time, then presence of a child, viewed solely as a reduction in available time without an offsetting utility flow, would raise the reservation wage as long as consurnption is a normal good. 
care market. ${ }^{10} \mathrm{I}$ interpret these facts differently. It is plausible that some women have low-cost, nonmarket substitutes available to care for their children. Potential sources of low-cost child care are relatives living nearby, husbands with flexible working hours, and friends and neighbors. The availability of these low-cost sources lowers the reservation wage and makes it more likely that women having such sources available will work.

Unfortunately, it is not possible to directly measure the price per unit quality women must pay for their child care. It is plausible to argue that all families can resort to the market to purchase units of child-care quality but that some families have informal sources available at a lower price per unit quality than is available in the market. Measuring quality by expenditure, we may normalize the market price at unity. ${ }^{11}$

Suppose the distribution of informal prices among the population at large is given by

$$
\ln p_{q}=X \beta+\varepsilon
$$

where $\varepsilon$ is a disturbance with zero mean and variance $\sigma_{\varepsilon}^{2}$ and where $X$ is a vector of variables assumed to affect the price per unit quality of child care. If we assume that the family selects its source of child care by the rule $\min \left(0, \ln p_{q}\right)$, the marginal rate of substitution function at the prework level of utility for families using informal sources $\left(\ln m_{I}\right)$ may be written as

$$
\ln m_{l}=\alpha_{0}+\alpha_{1} X \beta+\alpha_{2} Y+\alpha_{3} h+\alpha_{4} Z+u+\alpha_{1} \varepsilon,
$$

while the function for women using formal sources ( $\ln m_{I I}$ ) may be written as

$$
\ln m_{I I}=\alpha_{0}+\alpha_{2} Y+\alpha_{3} h+\alpha_{4} Z+u
$$

where a restriction on the distribution of $\varepsilon$ arises from the condition that

$$
\ln p_{q}<0 \rightarrow X \beta+\varepsilon<0 .
$$

It is possible to estimate $\beta / \sigma_{\varepsilon}$ from data on whether or not a family uses informal child care when the wife works. However, further information is required to estimate the coefficient $\alpha_{1}$ alone, ${ }^{12}$ although it is possible to estimate $\alpha_{1} \sigma_{\varepsilon}$. Since $\sigma_{\varepsilon}$ is known to be positive, it is still possible to test the hypothesis that $\alpha_{1}$ is positive.

10 In particular, Nelson and Krashinsky (1972) argue this position.

11 This procedure is clearly open to debate but is conventional. It assumes that quality is an objective characteristic and that units of quality are available at prices independent of the level of quality or the number of children.

12 To see this, note that we can estimate $\alpha_{1} \beta$ from eq. (7) and $\alpha_{1}^{2} \sigma_{6}^{2}$. Suppose, as is asserted in the text, we know $\beta / \sigma_{8}$. Then, from the "intercept term" we can estimate $\alpha_{1} \sigma_{\varepsilon}$, and from the variance we can also estimate $\alpha_{1} \sigma_{\varepsilon}$ if $\varepsilon$ is independently distributed from $u$, but we cannot determine $\alpha_{1}$ independently from $\sigma_{8}$ unless we assume further information. One possible assumption is that $\sigma_{\varepsilon}=1$. 


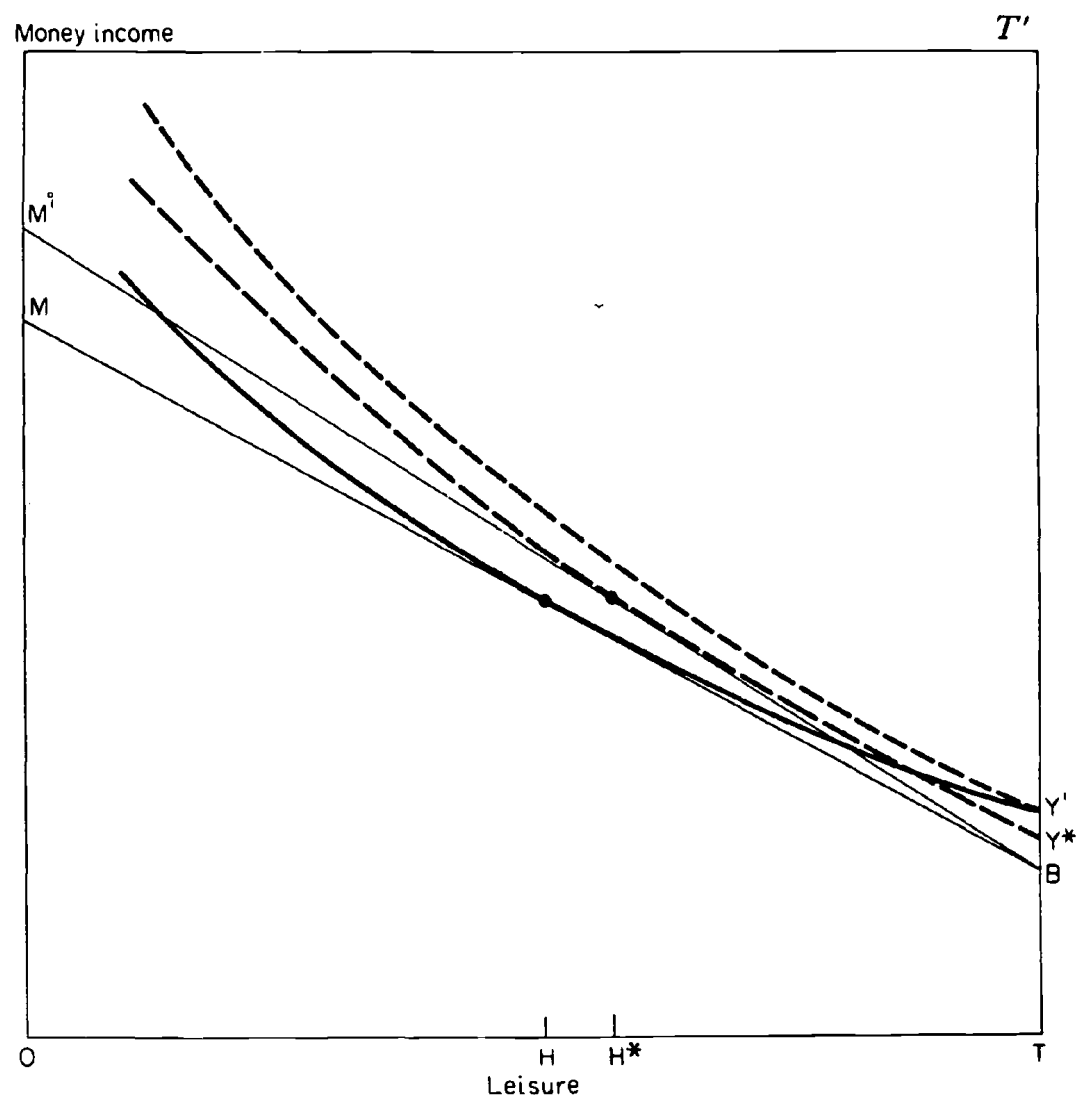

FIg. 2

Suppose that we can successfully estimate the relevant parameters of equations (7) and (8), including $\alpha_{1} \beta$. We can use these functions to address the problem, raised in Section $I$, of restricted vouchers. If a government program raises the wage rate of a woman with a child and insists that she use formal child-care sources, it is equivalent to a pure wage change for a woman already using formal sources but involves a change in $p_{q}$ to unity ( $\ln p_{q}$ to zero) for a woman not using these sources. From estimates of the indifference surfaces we can determine whether or not (on average) a woman using informal sources would switch to formal sources, because we can estimate the equilibrium position for hours of work in the case where she gets a higher wage but must pay a higher price for child care and the case where she abstains from the program. Having determined her equilibrium hours of work and wage rate in each situation, we can use equations (7) and (8) to determine the $Y^{*}$ (the amount of money income without work that would put the women at the same level 
of utility as working would) implicit in each situation. Since $Y^{*}$ serves as an index of utility, the situation with the higher $Y^{*}$ is the preferred situation and will be chosen. This approach is exact only if a woman spends nothing on child care when she does not work; it is approximately correct if child care is a small fraction of family expenditure when the woman does not work.

To see this more explicitly, consider figure 2 which, is similar to figure 1 . Consider a woman-facing budget constraint $M B$ and working $T H$ hours. The government raises her wage but simultaneously increasesthe price of work-related child care. In terms of this diagram, the effect of the price change is to shift "preferences" as shown by the dashed lines and to raise the wage so that the new budget line becomes $M^{\prime} B$. A new equilibrium position emerges along isoquant $Y^{*}$, using the "new" system of preferences. Using the estimated labor-supply curves, we can deduce that $T H^{*}$ hours would be worked. Further, using the new equilibrium values, we can deduce level $Y^{*}$ from equation (8). Then we can determine which situation is preferable since it is assumed that child-care expenditure is a negligible portion of consumer expenditure if a woman does not work, so that the effect of changes in the price of work-related child care is to pivot the indifference map around the intercept on the $T T^{\prime}$ axis. As the diagram is drawn, the woman abstains from the program since $Y^{*}$ lies below $Y^{\prime}$. Precisely the same methodology may be used in analyzing tied offers.

\section{Life-Cycle Modifications}

Assume an additively separable lifetime-preference function which may be represented as the (time preference) discounted sum of utility functions at each age. ${ }^{13}$ In this specification, utility at one age is not directly affected by variation in the consumption of time and goods at other ages. However, given a lifetime budget constraint, increasing consumption at one age reduces resources available at all other ages.

Within the context of this model, it is heuristically convenient (and formally correct) to imagine the consumer maximization process as a two-stage affair: subject to any income allotment, the family maximizes its utility within each period. To determine its allotment among periods, the family allocates income to equalize the marginal constribution to lifetime utility of an additional dollar of income in all periods if it is free to transfer resources among periods at a given borrowing and lending rate.

To account for the mobility of funds among periods, we must allow for saving or dissaving in a given period. For example, by borrowing against

13 This specification is widely used in the optimal-growth literature (e.g., Shell 1967) and the operational-utility literature (e.g., Strotz 1957). 
future income, households may enhance current resources. By saving, households transfer some of the current flow of resources to future time periods. Accordingly, the budget line in the conventional labor-leisure diagram (see fig. 1) must be shifted up (down) by the amount of net debt accumulation (saving) in the period. If saving is set at zero, the traditional one-period model retains its validity in a life-cycle context. ${ }^{14}$

Assuming that, there is no saving or borrowing is restrictive but traditional. It simplifies the analysis but is not necessary to it. Since the value of saving at any age depends on all prices, wages, and exogenous incomes, including the current wage, the current wage enters the analysis in two ways: as a direct determinant of work effort through the slope of the budget constraint, as in the traditional analysis, and as a determinant of the level of the given period's budget constraint through its effect on saving. Thus, in addition to the usual income and substitution effects confined to one period, there is an intertemporal income-transfer effect of wage change.

Introducing intertemporal considerations alters the simplicity of some of the previous analysis. In particular, consider the effect of a government program which raises the wage rate for women at an age at which children are present and simultaneously requires that the woman use approved child-care sources. In a one-period context we are able to solve the implicit level of utility, indexed by $Y^{*}$, under each program and are able to conclude whether or not a woman participates in such a program. In an intertemporal context we lose this simple feature because it is possible for $Y^{*}$ to be lower in one time period but for the resulting earnings flow to be sufficiently higher to more than compensate the woman by enhancing her future utility. Thus, we encounter an intertemporal indexnumber problem.

To illustrate this point, consider figure 3 . The dotted indifference curve represents the goods-leisure trade-off at a given period. The solid curves are the indifference system after the price per unit quality is raised. Consider a woman initially in equilibrium at point $B^{\prime}$, where $T K$ is the flow of earnings from other sources minus saving in the period. Holding saving fixed, raise the wage so that the new equilibrium is $B^{\prime \prime}$. As drawn, $B^{\prime \prime}$ is at a lower level of current utility than $B^{\prime}$. Yet, if earnings are increased sufficiently, the woman might still opt for the program, since she can transfer resources to future time periods and enjoy greater utility. If this is the case, the budget line shifts down by the amount of saving

14 For a proof of these propositions, see Heckman (1971) where the Strotz "utility tree" is applied to an intertemporal labor-supply problem. The assumption of additive separability yields a traditional labor-leisure diagram for each period in the consumer's life cycle. The level of the budget constraint in each period is determined, in part, by exogenous income flows in that period and the net transfer of resources into or out of the period. 


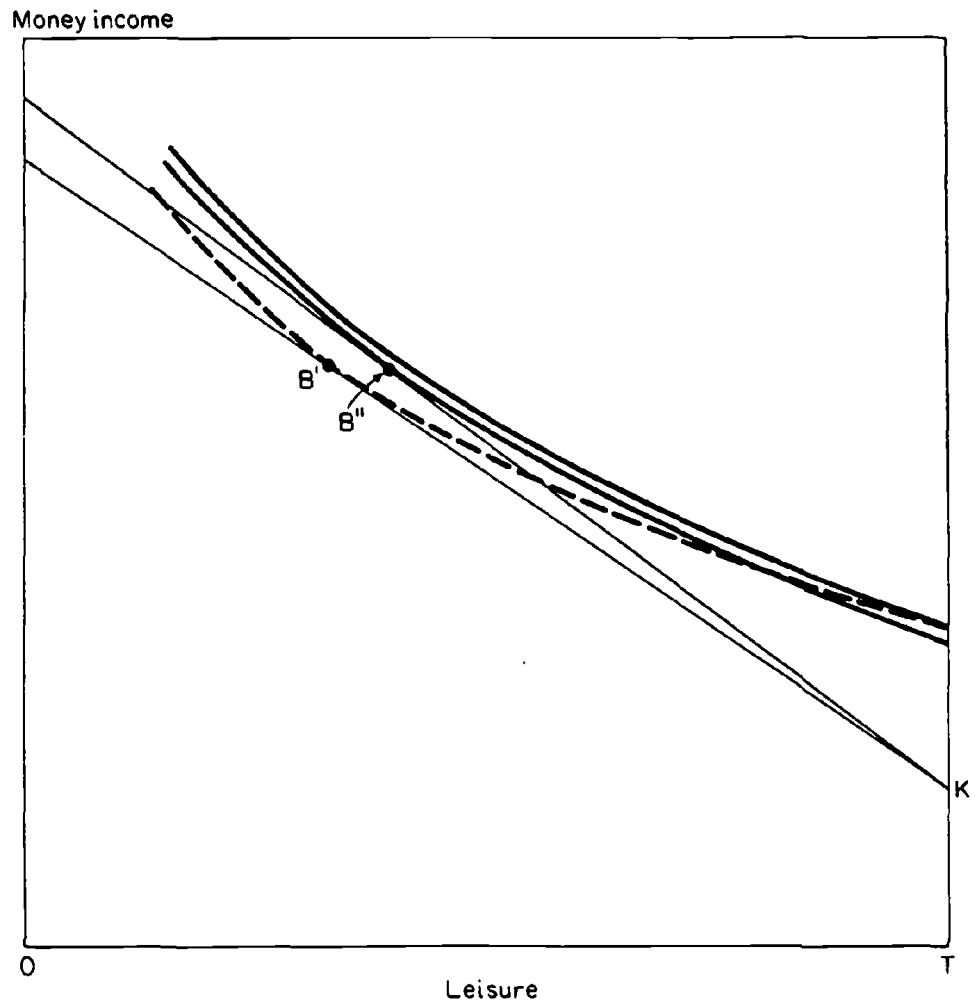

Fig. 3

and the woman works more since leisure is a normal good in each time period. Note, however, that if saving is held fixed, and the wage increase leads to a higher level of utility in this period, the possibility of transferring funds among periods enhances the attractiveness of the program so that a woman will definitely choose to participate in it and thus we can estimate a lower bound on the number of program participants. Note, too, that we can estimate an upper bound: take all women who are made worse off in this period and assume they participate in the program. Solving their new equilibrium values, allowing for a transfer of resources among periods, we can solve for their new earnings. If we also estimate their expenditure on child care, their earnings net of child-care expenditure (in the new program) must increase for resources to be freed to transfer to subsequent periods. Then we know that only women who have such options will participate in the program, although clearly not all of these women will participate.

The only necessary modification in the previous empirical specification is the introduction of a savings function which is subtracted from the 
exogenous income flow $Y$. In the absence of data on saving, we are forced to estimate an implicit savings function.

\section{Estimates}

Estimates of the one-period model developed in Section II are presented below. The estimation of the complete life-cycle model is left for another occasion. $^{15}$

Before presenting the estimates, it is useful to stress the restrictive nature of some of our assumptions. The assumption that the wage rate is independent of hours of work ignores the effect of progressive taxation. However, as noted in Appendix B, this defect can be remedied. A potentially more serious problem is our treatment of employer behavior. If firms incur fixed costs per worker, they are not indifferent to alternative combinations of men and hours per man which yield the same total man-hours (Rosen 1968). Under these circumstances, firms might pay higher hourly wage rates for longer weekly hours, at least up to certain levels of weekly hours worked. Thus, it is possible that the equilibrium condition invoked in Section II, that wage rates equal the marginal rate of substitution for working women, might not apply. This consideration creates a potentially important complication which is ignored in this paper. ${ }^{16}$

As Gronau notes, both the presence of fixed costs of work and the possibility of endogeneity of husband's earnings create potentially important biases (Gronau 1973, p. S177). These factors could be accommodated within our framework but only at much higher computational cost.

The data used to form the estimates are from the National Longitudinal Survey (NLS) of 1966 for women aged 30-44. The functions are estimated on a subsample of women who were married, spouse present, with at least

${ }^{15}$ An attempt was made to estimate a full-fledged life-cycle model on a cross section of data. In principle, this is a simple exercise. In practice, since the necessary savings data are missing, it is necessary to specify a savings function, which depends on current and future wage rates and exogenous income flows and on current-asset variables. The additional wage and income variable introduced in eq. (5) as determinant of saving led to unstable estimates. In fact, plausible alternative specifications for the savings function lead to underidentification for some parameters. These results suggest that we are asking too much of the data from one cross section. When the second-year data from the National Longitudinal Survey are available, it will be possible to estimate a separate savings function and get reliable estimates of the complete model.

${ }^{16}$ If there were a fixed standard work week, the analysis of Section II could be generalized to accommodate this complication. For those working fixed hours, and not moonlighting, the marginal rate of substitution evaluated at the standard work week (which depends, among other things, on the income flow from work and length of time at work) is less than the potential moonlighting wage, while for moonlighters the opposite is true. Thus, as shown in Appendix B, it is possible to gain some information about consumer preferences even when the marginal equality conditions no longer apply. 
one child under age 10. This subsample is chosen for two reasons. The principal reason is that it is a population obviously affected by childcare programs. ${ }^{17}$ Previous studies (Ruderman 1968; Bowen and Finegan 1969; Gronau 1973) suggest that only younger children exert an important retarding effect on women's work effort. A second reason for this choice of sample is closely related to the first. The NLS data give information on the availability of informal sources of child care, defined as care by relatives or zero (dollar)-cost day care. A unique feature of these data is that, in addition to questions asked on the type of child care used by working women, questions concerning the availability of informal sources were asked of nonworking women as well. It is computationally and conceptually more difficult to incorporate in our sample women for whom child care is an irrelevant issue.

In Appendix A I present an estimation method that incorporates the information that (1) the reservation wage is less than the offered wage and (2) the price per quality unit for child care is less than that available in the market. Both types of sample-inclusion criteria create the potential of censoring bias, but this is avoided by the procedure used.

By the construction of the sample, the presence of at least one child younger than age 10 is assured. To allow for scale effects, I created separate variables for number of children aged $0-3,4-6$, and $7-10$. Other children variables led to unstable estimates. Husband's earnings are added to net worth multiplied by an estimable flow coefficient to approximate the flow of exogenous income relevant to a one-period model.

Michael (1973) has argued that education may affect the household's ability to organize and produce its final consumption. To accommodate this hypothesis, I present estimates which measure the effect of the education (in number of years) of the wife on the marginal rate of substitution between goods and leisure. I contrast these results with more conventional estimates which exclude education from household preferences.

In order to include in the sample nonworking women for whom wage data are missing, it is also necessary to estimate a function for the market wages of all women. Its specification is kept simple. The natural logarithm of wages is postulated to depend on education and labor-market experience. ${ }^{18} \mathrm{I}$ explicitly allow for correlation between the disturbances of the preference function and the wage function.

A novelty of the procedure used is the explicit estimation of an informal child-care price function (discussed in Section II). Previous studies (e.g.,

17 However, the most relevant policy population is women on welfare who have young children. Small sample size and ignorance of the features of the welfare system confronting poor mothers precluded estimation on this sample.

${ }^{18}$ For a discussion of the experience variable, see the paper by Mincer and Polachek in this volume. I aggregated their segments of experience into a total-experience variable. 
Bowen and Finegan 1969) have shown that children aged 14-18 serve as stimulants to married female labor-force participation, and it is plausible that they supply a ready source of child care. Similarly, it is plausible that relatives living in the home, husbands with flexible working hours, and friends serve as low-cost sources of child care (see Low and Spindler 1968; Ruderman 1968). Accordingly, these determinants of the qualityadjusted price of day care are incorporated in the estimation.

To capture the effect of relatives on the price of child care, I created a dummy variable which assumes the value of one when a sister, parent, or grandparent lives in the household. The number of children aged 14-18 is included as a variable. As a crude measure of the flexibility of the husband's hours and his availability for child care, I use the number of hours he works in a week. As a measure of the availability of low-cost care from friends and relatives living nearby, I use two variables: a dummy which assumes the value of one when a woman has lived in a Standard Metropolitan Statistical Area (SMSA) all her life and a continuous variable measuring the number of years a woman has lived in an SMSA. Both are expected to depress the price of child care.

The estimates are presented in table 1. Column 1 reports estimates of the parameters for whites obtained by excluding the effect of education from household preferences, while column 2 shows the effect of including education. Comparable results for blacks are in columns 3 and 4 .

Consideration of column 1 coefficients for whites will illustrate the meaning of the coefficients. A unit increase in the logarithm of the quality-adjusted price of child care divided by its standard error raises the marginal rate of substitution by 14.3 percent. Each $\$ 10,000$ of exogenous income raises the marginal rate of substitution by 22 percent. Each 1,000 hours worked raises the marginal rate of substitution by 51 percent. An additional child aged 0-3 raises the marginal rate of substitution by 24.3. percent; an additional 4-6-year-old child raises the marginal rate of substitution by 8.4 percent, while an additional child aged 7-10 raises it only 2 percent. The coefficient on assets is a number converting the stock of net worth into a flow yield. Thus, if a family has $\$ 10,000$ worth of assets, the estimated income flow is $\$ 380$. This flow is added to other exogenous income flows in calculating the effect of income on the marginal rate of substitution.

Similarly, the coefficients for the quality-adjusted price of child care show the effect of the associated variables on percentage changes in this price divided by the standard error of the price distribution. Older children, relatives living in the home, and length of residence in the SMSA all have the expected negative effects on this price while the other coefficients cannot be deemed significant by conventional standards.

The estimates for the market-wage function show the effect of the associated variables on the natural logarithm of market wages. The 
population correlation coefficient measures the interequation residual correlation between the market-wage function and unmeasured tastes for work.

In comparing columns 2 and 1 , it is seen that while conventional significance tests suggest that education should be included in household preferences, its inclusion alters few coefficient estimates. The only notable exception is that the effect of education on market wages is increased and is not significantly different from the effect of education on reservation wages. This suggests that for white women with at least one child younger than age 10, better-educated women do not work in the labor force as much as less educated women. For comparable black women, bettereducated women are more likely to work.

The most useful way to summarize these numbers is to consider their potential application. Making the bold assumption that the preference parameters for married black women with spouse present are those appropriate to all black women, we can investigate the possibility of using tied child-care offers to alleviate welfare dependency. Consider a group of black women currently eligible for an annual welfare payment of $\$ 3,000$. For the sake of illustration, we assume that each woman has three children-one in each of our estimated age intervals. We assume that each woman uses informal child-care sources and that she has one child from 14 to 18 years old, one older relative living in the home, and that she has lived in her current SMSA for 8 years. We further assume that each woman has no asset income and 10 years of schooling.

Each woman has a choice of working or taking welfare. The geometric mean indifference curve appropriate to potential welfare recipients is sketched as $A A^{\prime}$ in figure 4 . Fifty percent of the potential welfare recipients have an indifference curve emanating from $A(=\$ 3,000)$ which lies below $A A^{\prime}$. Twenty-five percent of the group have an indifference curve starting at $A$ which lies below $A C$. This latter group may be termed the most "work prone" because they require less compensation to be induced to work. Again, solely for the sake of argument, suppose that each woman has an identical wage of $\$ 1.50$ per hour which she can earn in the market. More realistically, we might assume a distribution for wages as well.

In this extreme example not all women will choose to go on welfare. The few who are not on welfare will be observed to work long hours at low wages. Again, solely for the sake of argument, suppose no women work. Suppose the government offers an unrestricted "day-care" voucher to a woman if she works 1,500 hours. From budget line $O B$ we can see that if the woman were to work 1,500 hours at $\$ 1.50$ per hour she would earn $\$ 2,250$. The minimum compensation beyond her own earnings that would be necessary to induce half the women to leave welfare is the distance $B^{\prime \prime} B^{\prime}(=\$ 3,300)$. Note, however, that if a $\$ 2,560$ child-care subsidy were offered $\left(=B^{\prime} B^{\prime \prime \prime}\right) 25$ percent of the women would leave 


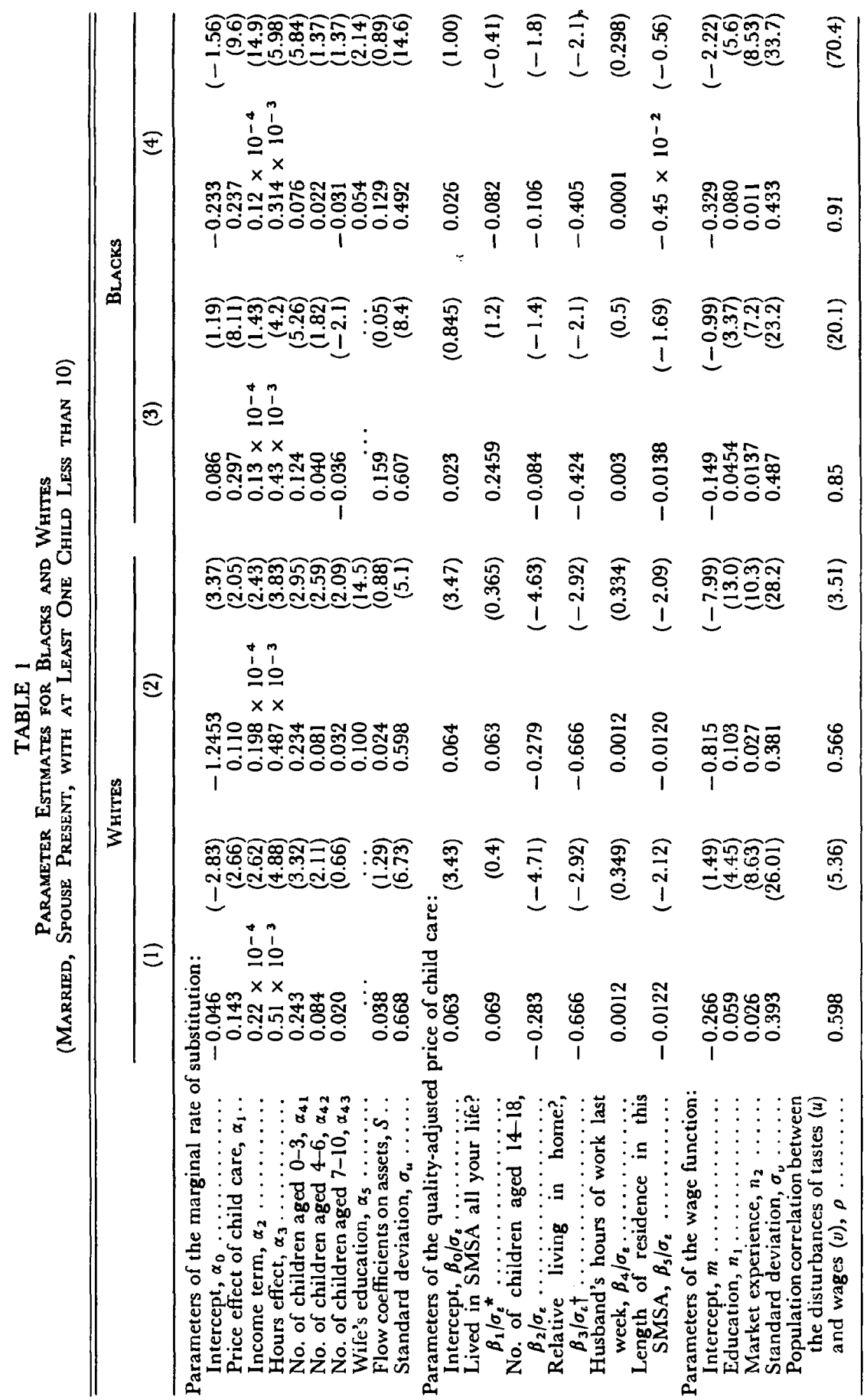


Do not work, would use formal sources $\ddagger \ldots \ldots \ldots \ldots$

Do not work, would use informal sources ............

Work and use formal sources ................

Work and do not use formal sources .............

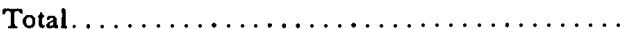

\begin{tabular}{lr}
248 & 87 \\
148 & 62 \\
104 & 45 \\
293 & 187 \\
\hline 793 & 381
\end{tabular}

Sources.--Data are from 1967 National Longitudinal Survey of Work Experience of Women aged 30-44. For a description of these data, see Dual Careers (Parnes, Shea, Spitz, and Zeller 1970).

NoTe. - Numbers in parentheses are asymptotic normal statistics estimated from the information matrix. $* 1$ if yes; 0 if otherwise.

$t=1$ if sister, parent, grandparent; 0 if otherwise.

† Formal sources are defined as paid care at child-care centers and care at a nonrelative's home. Informal sources include all other sources. Nonworking women are classified into two groups: those looking for work (group B) and those not looking for work (group C). Everyone in the first group was asked whether or not child-care arrangements would be necessary and what type of arrangenients would be made if they were necessary. This allowed for a classification broadly consistent with the classification of actual use for working women. Information on the group not looking for work is more scarce. To be included in the sample they had to answer "yes" or "it depends" to a hypothetical question about whether they would work if a job were offered to them (Parnes et al. 1970, question 30a, p. 260) and a subsequent question on need for child care and what form would be used (question 31). To determine whether the composition of the sample was biased by using this inclusion criterion, separate discriminant functions were fitted by race for all married women with at least one child younger than 10 years old in group $\mathbf{C}$. Respondents were distinguished from nonrespondents by a set of variables including the number of children in different age intervals, assets, age and education of wife, and husband's earnings. The only significant discriminants for both races were assets and the number of children aged 0-3 years. Both variables tended to be larger for nonrespondents. Accordingly, the coefficient estimated reported in this table may be biased. In my opinion, the added information about potential child-care sources for nonworking women was worth the risk of bias.

welfare voluntarily, and the welfare cost to society at large would diminish by $\$ 440$ per person who leaves welfare. ${ }^{19}$ Clearly, in this case there is scope for using tied offers to reduce welfare dependency. The transferminimizing policy is Pareto optimal and is straightforward to determine. ${ }^{20}$ Note, too, that we can determine what proportion of women will work beyond the minimum number of hours needed to qualify for the program. Consider a woman whose indifference curve is $A C$. At 1,500 hours of work, the slope of the indifference curve (at $B^{\prime \prime \prime}$ ) exceeds $\$ 1.50$, so that if she were given slightly more than $\$ 2,540$ she would leave welfare and work

19 Remember that it was assumed that all women were on welfare. In reality, only some fraction of this 25 percent would be.

20 For each value for hours worked, $h$, a child-care bonus $B$ determines a proportion of welfare clients $P(B)$ who will leave welfare, given that bonus. Clearly, $B$ lies between zero and $\$ 3,000$, the welfare payment. The mean transfer to the group is $P(B) B+$ $[1-P(B)](\$ 3,000)$. Minimizing mean transfer is equivalent to minimizing group transfer since I assume no discrimination within the group is possible. For each $h$, there will exist a $B$ which minimizes mean transfer, and the minimum mean transfer for all $h$ can be determined. Thus, knowing the distribution of preferences, it is possible to simultaneously determine $B$ and $h$. Under general conditions, there exists a unique Pareto-optimal policy for tied welfare offers which can be estimated from the data. Note that, in the example, it is assumed that no one works initially. To determine the Paretooptimal tied offer if some work, it is necessary to subtract the transfers paid to those who would have worked without a child-care bonus. Note that Pareto optimality is used here in the restricted sense of improving community welfare from a current position; it is not the global optimality concept of general equilibrium theory. 


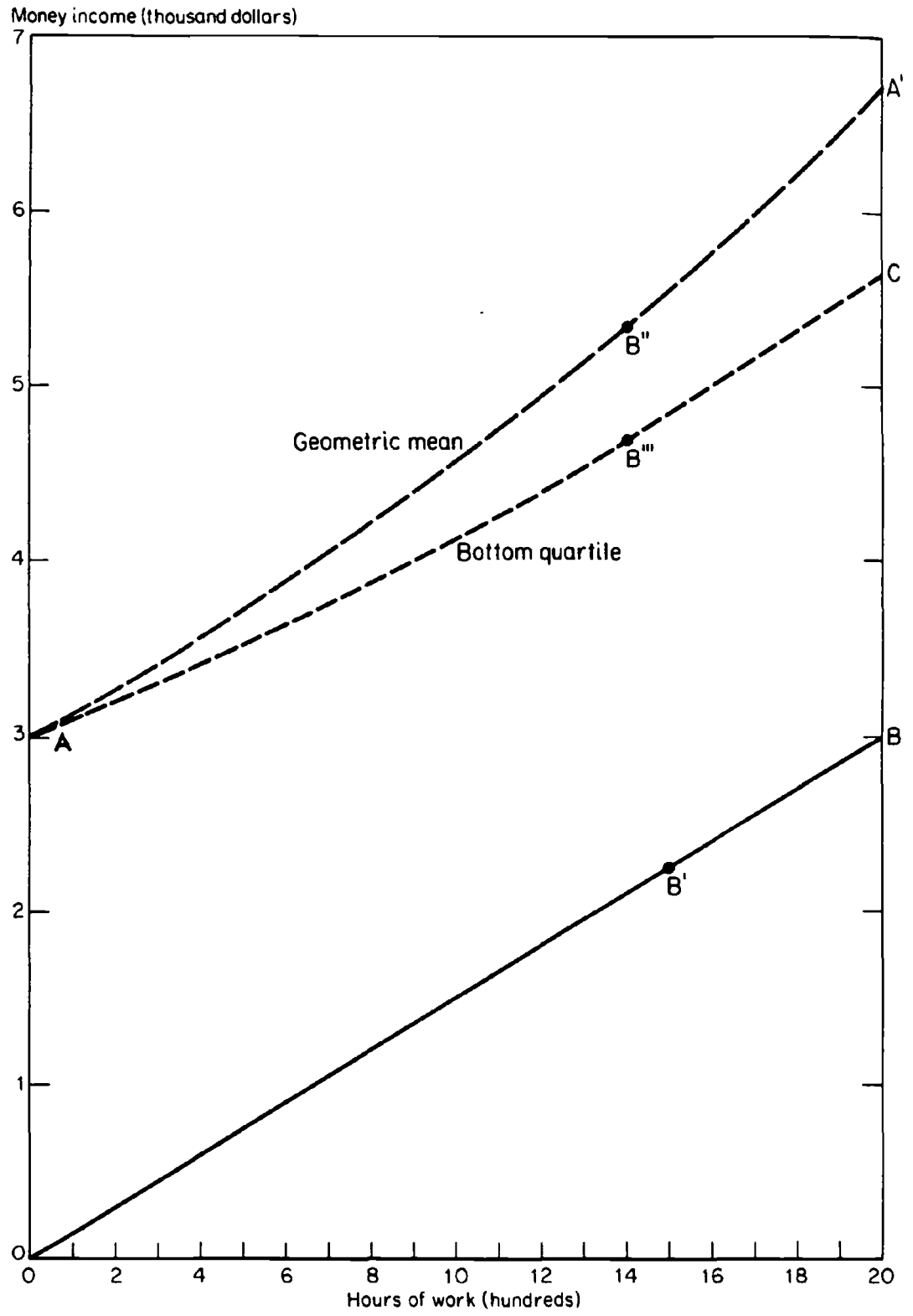

Fig. 4 


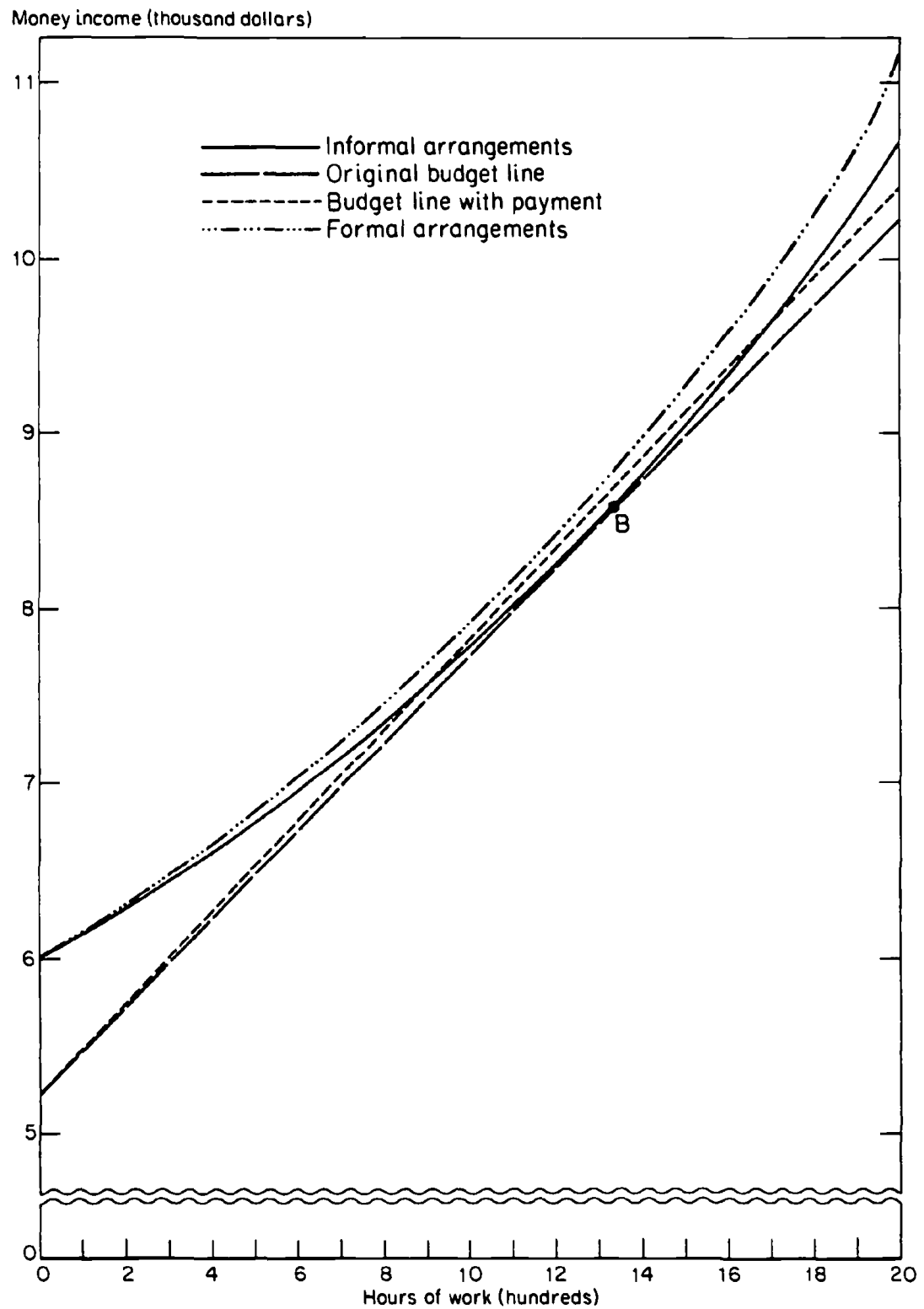

Fig. 5 
exactly 1,500 hours. The reason she would not work longer hours is that her reservation wage at 1,500 hours exceeds her offered wage of $\$ 1.50$.

As a further illustration of the use of the empirical results, consider a representative working white woman, using informal child-care sources, whose husband earns $\$ 5,500$ per annum. Suppose that she has 12 years of schooling, assets of $\$ 5,000$, and two children, one from 0 to 3 years old and one from 4 to 6 . In figure 5 , we plot a solid system of indifference curves appropriate to the case of lower prices for informal child care, drawn on the assumption that the woman has not lived in the SMSA all her life, that her husband works 40 hours a week, that a relative lives in the home, and that she has lived in her current SMSA for the last 10 years. Superimposed on this system is a broken-line indifference curve appropriate to the use of child care purchased in the formal market.

As the lines are drawn, the woman is in equilibrium at point $B$ earning $\$ 2.30$ per hour. Suppose the government raises her wage to $\$ 2.40$ per hour by providing a $10 \notin$ per hour child-care subsidy conditional on her use of formal sources. Will she take the offer? In this case, the answer is no. The dashed "program budget line" lies below the iso-utility contour for formal arrangements, equivalent in utility terms to the indifference curve for informal arrangements on which she previously was in equilibrium. Hence, she abstains from the program. Given the parameters of the distributions of the curves, we can make similar statements for groups as a whole and hence can estimate the proportion of working women currently using informal child-care sources who will switch to formal sources if only restricted vouchers are available. ${ }^{21}$

\section{Summary and Suggested Extensions}

The economics of tied work payments and methods for estimating the effect of such payments on labor supply have been discussed in this paper. It is important to distinguish the conceptually easier problem of modeling the response to tied offers from the more demanding problem of providing reliable estimates of the appropriate behavioral functions. It has been shown that knowledge of consumer preferences is necessary to estimate program effects, and methods have been suggested for determining these preferences.

By directly estimating indifference curves, hours of work and workparticipation equations have been derived from a common set of parameters. The separation of preferences from constraints allows us to estimate the labor-supply parameters of individuals from data generated by non-

21 To answer both policy questions fully would require consideration of the distributions of wage rates, preferences, and prices for child care. Such projections would be suspect at this stage of this research because the full tax-adjusted life-cycle model has not been estimated. 
standard constraints, such as the broken-line budget constraints resulting from the tax system, where a tractable labor-supply function does not exist. At the cost of estimating a savings function, we can embed the traditional one-period model of labor supply into a life-cycle model. Both the distribution of tastes for work and the distribution of market wage rates for the population at large are estimated. The estimates suggest that wage rates are strongly correlated with preferences for work so that simple "reduced-form" labor-supply functions obtained by regressing hours worked on wage rates give biased estimates. In forming estimates, a statistical procedure is employed which avoids this bias and the censoring bias discussed above.

Perhaps the most controversial aspect of this study is the treatment of the choice of the mode of child care. A latent distribution of informal prices for child care is assumed to exist in the population at large. It is further assumed that a competitive market in child-care quality exists so that individuals facing informal prices in excess of the competitive price use formal child-care sources if they work. The decision to work and the decision to use formal sources are related in the sense that the price of child care is a determinant of the decision to work and of the actual hours worked. This model enables us to use information on hours of work and the decision to work, in combination with direct information on the form of child care used by working mothers, to estimate the determinants of the mode of child care mothers select. The empirical results are consistent with this model but have not been tested against possible alternative models.

If families value the development of their children, and the mother's time is an important input into this development, custodial child care might be chosen if a mother works a limited number of hours but might be unacceptable if she works full time. If formal sources provide higherquality day care, the decision to work, the length of the work week, and the choice of the mode of child care are jointly determined and mutually dependent on the wage rate and the prices of formal and informal care. Although this alternative model is much more difficult to estimate, it is conceptually more attractive and contains the present model as a special case. For these reasons it is an approach that might prove fruitful in future research on the economics of child care.

\section{Appendix A}

\section{The Estimation Procedure}

The parameters of the marginal rate-of-substitution function (4) are estimated by a maximum-likelihood technique developed in a previous paper (Heckman 1972). In that paper, I present a method that permits observations on nonworking women to be pooled with observations on working women to estimate hours-of- 
work functions, work-participation functions, and wage functions for all women. The procedure avoids the bias that results from estimating wage and hours-ofwork functions using standard regression techniques on censored subsamples of working women.

Four distinct subsamples are considered here in contrast to the two subsamples considered in my previous paper. Some working mothers use informal child-care sources while others use formal sources. Potentially, the same dichotomy exists among nonworking women, and a unique feature of the data used here is that for many nonworking women it is possible to identify which mode of child care they would use if they were to work.

Letting $W_{1}$ be the wage rate for the $i$ th woman and using the notation of the text, woman $i$ works and uses formal sources of child care if

$$
X_{i} \beta+\varepsilon_{i}>0 \text { and } \ln W_{l}>\alpha_{0}+\alpha_{2} Y_{i}+\alpha_{4} Z_{i}+u_{i},
$$

where $X_{l} \beta+\varepsilon_{l}$ is the quality-adjusted price of child care. Woman $i$ works and uses informal sources if

$$
X_{i} \beta+\varepsilon_{i}<0 \text { and } \ln W_{i}>\alpha_{0}+\alpha_{1} X_{i} \beta+\alpha_{2} Y_{i}+\alpha_{4} Z_{l}+\alpha_{1} \varepsilon_{i}+u_{l} .
$$

For nonworking women who would use formal sources,

$$
X_{l} \beta+\varepsilon_{l}>0 \text { and } \ln W_{l}<\alpha_{0}+\alpha_{2} Y_{l}+\alpha_{4} Z_{l}+u_{l},
$$

while for nonworking women who would use informal sources

$$
X_{i} \beta+\varepsilon_{i}<0 \text { and } \ln W_{t}<\alpha_{0}+\alpha_{1} X_{i} \beta+\alpha_{2} Y_{l}+\alpha_{4} Z_{l}+\alpha_{1} \varepsilon_{i}+u_{i} .
$$

To circumvent the practical difficulty that wage rates are missing for nonworking women, I postulate a wage function for the ith individual,

$$
\ln W_{l}=m+n k_{i}+v_{i},
$$

where $k_{i}$ includes determinants of market wages such as education and labormarket experience, and where $v_{i}$ is a disturbance term with zero mean and variance $\sigma_{v}^{2}$.

To derive the appropriate sample likelihood function, consider the joint density of the disturbances $h(u, v, \varepsilon)$. For a working woman who uses formal sources, the density function for $u, v$, and $\varepsilon$ for the domain defined by (Al) is

$$
\frac{h(u, v, \varepsilon)}{\operatorname{Pr}\left(m+n k-\alpha_{0}-\alpha_{2} Y-\alpha_{4} Z>u-v \Lambda \varepsilon>-X \beta\right)},
$$

where $\operatorname{Pr}(\cdot)$ denotes the probability of event ".". Assuming independence between $\varepsilon$ and other disturbances, but allowing for dependence between $u$ and $v$, we may write $h(u, v, \varepsilon)=g(u, v) s(\varepsilon)$, so that the conditional density of $u$, $v$, and $\varepsilon$, given that a woman works and uses formal sources, may be written as

$$
\frac{g(u, v) s(\varepsilon)}{\operatorname{Pr}\left(m+n k-\alpha_{0}-\alpha_{2} Y-\alpha_{4} Z>u-v\right) \operatorname{Pr}(\varepsilon>-X \beta)} .
$$

The density function for observed hours of work, wages, and the event "use of formal child-care services" is readily derived. To simplify the exposition, I present only the distribution for $u, v$, and the use of child care, which is

$$
\frac{g(u, v) \int_{-x \beta}^{\infty} s(\varepsilon) d \varepsilon}{\operatorname{Pr}\left(m+n k-\alpha_{0}-\alpha_{2} Y-\alpha_{4} Z>u-v\right) \operatorname{Pr}(\varepsilon>-X \beta)} .
$$


For working women who use informal sources, it is more convenient to work with the density function

$$
b\left(u+\alpha_{1} \varepsilon, 0, \varepsilon\right),
$$

which can easily be derived from $h$. For expository ease, it is convenient to define $u+\alpha_{1} \varepsilon=c$. Clearly, $c$ is not independent of $\varepsilon$. This implies that the conditional distribution of $c, v$, and the dummy variable associated with the "use of informal sources" may be written as

$$
\frac{\int_{-\infty}^{-\infty} b(c, v, \varepsilon) d \varepsilon}{\operatorname{Pr}\left(m+n k-\alpha_{0}-\alpha_{1} X \beta-\alpha_{2} Y-\alpha_{4} Z>c \Lambda \varepsilon<-X \beta\right)} .
$$

We may combine observations described by (A8) and (A10) to form the conditional likelihood function for working women. To incorporate sample information for nonworking women, we know that the appropriate probability statement for nonworking women who would not use formal sources is

$$
\operatorname{Pr}\left(m+n k-\alpha_{0}-\alpha_{1} X \beta-\alpha_{2} Y-\alpha_{4} Z<c \Lambda \varepsilon<-X \beta\right),
$$

while for nonworking women who would use formal sources the appropriate probability statement is

$$
\operatorname{Pr}\left(m+n k-\alpha_{0}-\alpha_{2} Y-\alpha_{4} Z<u-v \Lambda \varepsilon>-X \beta\right) .
$$

We may combine observations described by (A8) and (A10) with observations on nonworking women by weighting the conditional densities by the probability of the conditioning event.

To form the sample likelihood function in terms of observable variables, substitute for $u$ and $v$ from equations (5) and (A5), respectively. The Jacobian of transformation is $\left|\alpha_{3}+\alpha_{2} W\left(1-e^{-\alpha_{3} h}\right)\right|$. It is straightforward to verify that since $h \geq 0$, the transformation is one-to-one since $\alpha_{2}>0$ and $\alpha_{3}>0$. Ordering the observations so that the first $T_{W F}$ work and use formal sources, the next $T_{W I}$ work and use informal sources, the subsequent $T_{N W F}$ do not work and would use formal sources, while the last $T_{N W I}$ do not work and would use informal sources, the sample likelihood may be written as

$$
\begin{aligned}
& =\prod_{i=1}^{T_{W P}}\left|\alpha_{3}+\alpha_{2} W_{l}\left(1-e^{-\alpha_{3} h_{l}}\right)\right| g\left(u_{l}, v_{l}\right) \int_{-x_{i} \rho}^{\infty} s(\varepsilon) d \varepsilon
\end{aligned}
$$

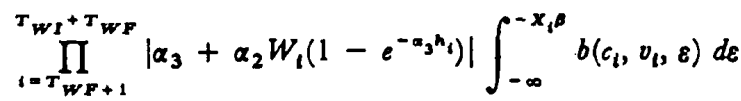

$$
\begin{aligned}
& \prod_{i=T_{W F^{+}} T_{W T^{+1}} \prod_{W l}+T_{N W F}} \operatorname{Pr}\left(m+n k_{l}-\alpha_{0}-\alpha_{2} Y_{l}-\alpha_{4} Z_{t}<u-v\right) \operatorname{Pr}\left(\varepsilon>-X_{i} \beta\right)
\end{aligned}
$$

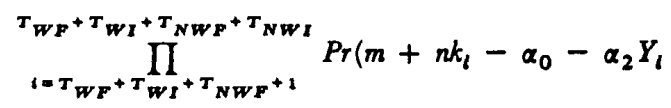

$$
\begin{aligned}
& \left.-\alpha_{4} Z_{l}<c_{l}-v_{l} \Lambda \varepsilon<-X_{l} \beta\right)
\end{aligned}
$$

where $u_{i}=\ln W_{1}-\alpha_{0}-\alpha_{3} h_{t}-\alpha_{4} Z_{i}-\alpha_{2}\left[W_{t} h_{t}+Y_{t}-\left(W_{l} / \alpha_{3}\right)\left(1-e^{-\alpha_{3} n_{i}}\right)\right]$, $c_{i}=u_{t}-\alpha_{1} X_{t} \beta$, and $v_{l}=\ln W_{l}-m-n k_{i}$. In deriving the estimates, I assume that the disturbances are jointly normally distributed, with $\varepsilon$ uncorrelated with $u$ and $v$. The precise functional forms are well known and are not presented here. Note that each term in the third group of products involves the product of two 
cumulative normals and hence is easily computed. The last group of products involves a bivariate normal density. Rather than using inexact and computationally expensive numerical quadrature to evaluate these expressions, I use a Chebyshev-Hermite orthogonal polynomial expansion to 100 powers (Kendall 1941). This procedure allows for a computationally simple algorithm which can readily be applied to more general multivariate probability statements arising from the normal distribution.

To perform the calcalations, two algorithms were used: the Powell conjugent gradient method and GRADX. The Powell method was used for initial iterations while GRADX was used to locate final optima. ${ }^{22}$

\section{Appendix B}

\section{Tax Rates and Welfare Systems}

In the text, I assume that the wage rate is independent of hours of work. My approach allows me to relax this assumption. Tax laws set rising rates of taxation on income intervals. For any wage rate, the income intervals can be converted into intervals for hours of work. Given an initial position for prework income, $Y$, the budget line is a broken line, illustrated in figure 6 .

If the wage rate is known, we know the intervals $t_{1}, t_{2}$, and so on. Suppose a woman's equilibrium position for hours of work is $C$. Since the budget constraint is concave, the slope of the first segment of the constraint must exceed the slope of the indifference curve intersecting $Y$ for a woman to work any hours. For a woman to work beyond $T t_{1}$ hours, exactly the same type of inequality condition must be met. The "reservation wage" for work in excess of $T t_{1}$ hours is partly determined by the value of hours worked and the known income $Y M$ which accrues if the woman works $T t_{1}$ hours at the given wage rate net of taxes. Thus, a second inequality must be satisfied for a woman to work beyond $T t_{1}$ hours. We acquire as many inequalities as there are breaks in the schedule. If a woman happens to be in equilibrium exactly at a switch point, the usual marginal conditions do not apply, but we can still acquire information about consumer preferences from such observations, since at the switch point, the marginal rate of substitution must lie between the slopes of the two segments of the budget constraint.

Since wage rates are known for working women, we can avoid bias due to censoring and incorporate tax rates into the estimation procedure by maximizing the appropriate conditional likelihood function. ${ }^{23}$ To illustrate the procedure, consider a woman in equilibrium at position $C$ in figure 6 . For the woman to be in equilibrium on this segment of the budget constraint, the marginal rate of substitution at the right boundary is less than the slope of the segment, while the marginal rate of substitution at the left boundary is greater than the post tax marginal wage rate for further hours of work. This imposes a condition on the range of the disturbances of the indifference system. It is straightforward to derive the conditional distribution for the indifference system in this segment and to form the appropriate conditional likelihood function.

Precisely the same method may be applied to welfare systems which impose similar "distortions" on the budget line.

22 For a discussion of these algorithms, see chap. 1 of the excellent book by Goldfeld and Quandt (1972).

${ }^{23}$ It is possible to have unknown wage rates, but the distributional problems become severe and they are not discussed here. 


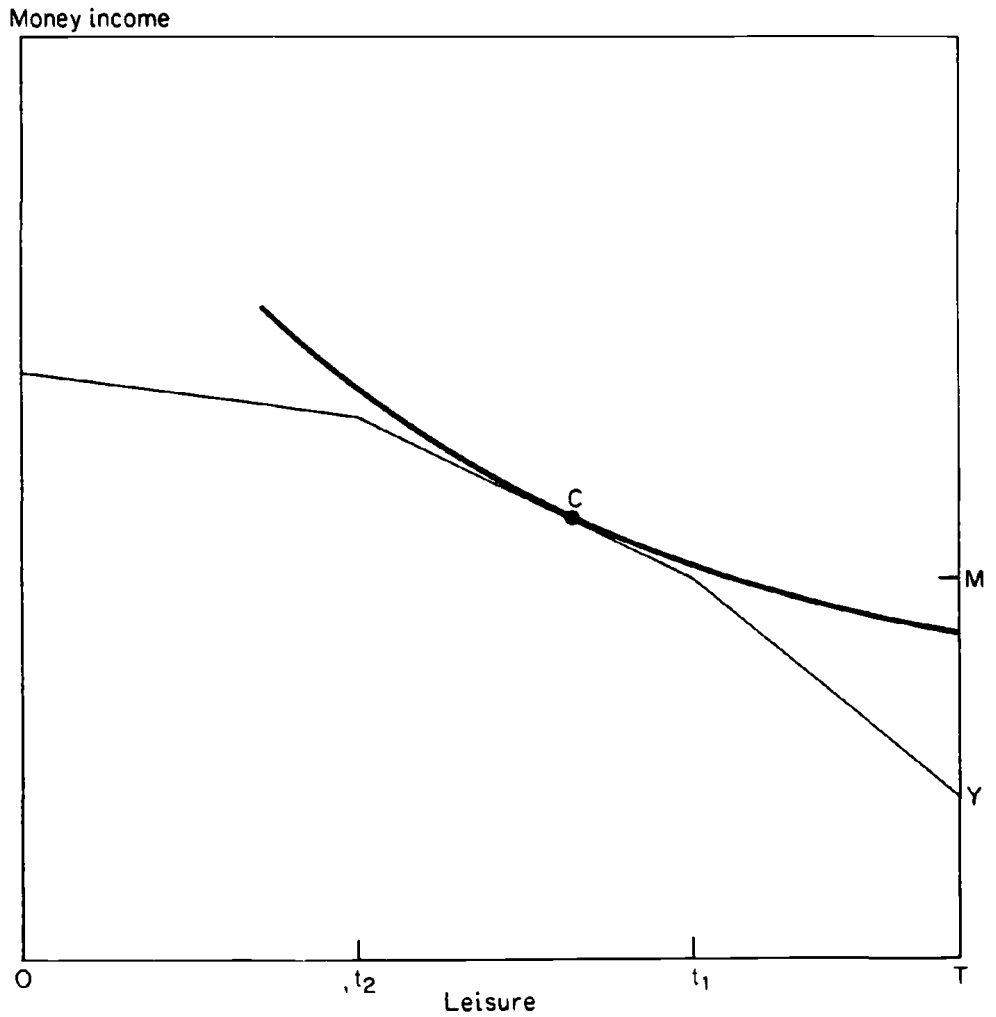

Fig. 6 


\section{Comment}

\section{Sherwin Rosen}

University of Rochester and Haroard University

Heckman has applied sophisticated theory and empirical methods to an important practical problem. He uses a variant of Tobit analysis to combine qualitative data on labor-force status with quantitative data on hours of work. These methods not only take account of the usual differences in market wage opportunities confronting individuals, but also account for differences in tastes among them. Few previous labor-supply studies have attempted to incorporate variations in tastes, and virtually none has treated the problem with other than ad hoc methods. In addition, Heckman's statistical approach directly addresses a problem of interpretation raised by Lewis (1972): Cross-section regressions of labor-force participation rates on wage rates and other variables do not necessarily capture underlying substitution effects between leisure and goods. For example, suppose there are differences in preferencesor home productivities among members of the population under study, over and above those represented by such exogenous variables as education and number of children. Then there is a distribution of unobserved reservation wages. Those whose reservation wage exceeds available market wages choose not to participate in the labor market. They specialize in home production and leisure instead. As wages increase, the fraction of the population satisfying this criterion decreases and labor-force participation rates rise. Therefore, wage variation in the sample sweeps out a tail of the underlying distribution of reservation prices. Regression estimates may only give us back properties of this distribution and may be uninformative with respect to the more interesting aspects of the structure of preferences. Heckman explicitly deals with this problem in his analysis. Furthermore, both labor-force status and hours-of-work data are utilized efficiently in estimating labor-supply parameters. I know of no other work that utilizes the sample information in this way. 
Heckman does not rest content at this point. He offers some conceptual modifications as well. Predictions of labor-supply responses to child-care programs require more knowledge than the uncompensated supply function, because these programs introduce a complicated wedge between average and marginal wage rates. However, no difficulties arise if the whole preference map or, what amounts to the same thing for prediction purposes, the utility compensated supply function for hours of work is known. The paper gives the impression that parameters of indifference curves are estimated directly. However, appearances are deceiving. Under the assumptions of the model, the plain fact is that the observations are generated by an uncompensated, garden-variety supply function. Conversely, the data identify an ordinary supply function, not an uncompensated one. The latter, as well as indifference-map parameters, always must be inferred from the former, using the theory of revealed preference. Since most of this theory is found in rather inaccessible discussions of integrability and related topics, it is worthwhile to spell out some details in a simple case.

A decision maker maximizes a quasi-concave utility function $u=U(x, h)$ subject to the constraint $x=w h+y$, where $h$ is hours of work, $x$ is all other goods, $w$ is the wage rate (in terms of units of $x$ ), and $y$ is nonlabor income (also in units of $x$ ). ${ }^{1}$ Necessary conditions are $U_{x}=\lambda$ and $U_{h}=-w \lambda$, where $\lambda$ is the marginal utility of income. These conditions and the budget constraint imply a set of uncompensated demand and supply functions,

and

$$
x=f(w, y)
$$

$$
h=g(w, y) .
$$

It is equation (2) that generates the labor-supply observations. Equations (1) and (2) are not independent of each other. Substituting into the budget contraint and differentiating gives

and

$$
w g_{w}-f_{w}=-g
$$

$$
-w g_{y}+f_{y}=1 \text {. }
$$

Define an indirect utility function by substituting the demand and supply functions into $U(x, h): u=U[f(w, y), g(w, y)]=V(w, y)$. Totally differentiate $V(w, y), d u=\left(U_{x} f_{w}+U_{h} g_{w}\right) d w+\left(U_{x} f_{y}+U_{h} g_{y}\right) d y$, and sub-

1 Alternatively, $U(x, h)$ can be a synthetic utility function, after optimizing out the child-care quality decision conditional on $h$. That is the approach followed by Heckman. Then the quality price of child care is a proper argument of $U$, but is suppressed in this discussion. 
stitute the necessary conditions plus restrictions (3) and (4). Simplification yields the result

$$
d u=\lambda[g(w, y) d w+d y] .
$$

What combinations of wage rates and nonlabor income results in the same level of utility when consumption-labor choices are optimal? ${ }^{2}$ Setting $d u=0$ in (5) and using the fact that $\lambda>0$, these values must satisfy

$$
d y / d w=-g(w, y) .
$$

Equation (6) defines the marginal rate of substitution between $w$ and $y$. It gives the slope of an "indifference curve" between $w$ and $y$ rather than between $x$ and $h$. Notice that the slope only depends on $h=g(w, y)$, which is known and estimated from the data. ${ }^{3}$ Now treat equation (6) as a differential equation in $y$ and integrate to obtain

$$
y=F(w, c),
$$

where $c$ is a constant integration, dependent on the initial state $\left(w_{0}, y_{0}\right)$. The conditions under which a solution exists are minimal and almost certain to be satisfied by any empirically tractable supply function. In fact, (7) is the equation of the indirect preference map and $c$ is a utility indicator: $F(w, c)$ is an inverse of the indirect utility function. Once the uncompensated supply function $h=g(w, y)$ has been estimated, $F(w . c)$ can be obtained without prior knowledge of the utility function by integration, if not analytically, then with numerical methods on a computer. Finally, substitute equation (7) into equation (2),

$$
h=g[w, F(w, c)]=G(w, c) .
$$

Equation (8) is the utility-compensated supply function for hours of work and $G_{w}=g_{w}+g_{y} F_{w}=g_{w}-h g_{y}$ is the pure substitution effect. Alternatively, solving for $w$ in terms of $h$ and $c$ in equation (8) yields the marginal rate of substitution function, the form used by Heckman. Note that (8) or its inverse is inferred only from knowledge of the uncompensated supply function.

The discussion above shows how it is possible to learn something about the utility function purely from observing the uncompensated supply function. Heckman's procedure is more or less the opposite. He begins with a functional form restriction on the preference map (i.e., a restriction on equation [8] -his equation [4]) and integrates back to an uncompensated supply function (his equation [5], comparable with equation [2] above). It is the latter that is estimated. His restrictions are such that

\footnotetext{
2 The following development is a variant of an argument due to Hotelling (1932).

3 Differentiation of (6) reveals that $d^{2} y / d w^{2}=-\partial h / \partial w+h(\partial h / \partial y)$. This is the negative of the pure substitution effect and the wage-nonlabor income indifference curves are concave to the origin.
} 
estimated parameters of the uncompensated supply function exactly identify parameters of the preference map without further manipulation. Of course the theory does not specify precise functional forms, and some prior specifications are necessary for estimation. The compensated and uncompensated supply functions stand in a one-to-one relationship, and a functional form restriction on either one implies a corresponding restriction on the other. Thus, the question boils down to where one should impose the restrictions in practice. My own preference is to put the functional form restrictions on the uncompensated supply function and work back from that to the compensated function. After all, the observations directly identify only the uncompensated supply function, and, in the nature of the revealed preference argument, the structure of preferences only can be inferred indirectly from observed behavior. There really is no way out of a specification search at the point of observations. We simply have no way of knowing whether semilog linear preference maps are appropriate. The proper specification must come from observed, uncompensated behavior.

Heckman's restriction makes the generating function of the observations (his equation [5]) nonlinear and difficult to estimate. Computational difficulties are compounded by incorporating observations on labor-force nonparticipants. On the other hand, predictions of various program effects are more easily computed. If one starts from the other end, as suggested here, estimation is far less costly, and much greater experimental flexibility is achieved at the stage where that experimentation is most desirable. But this has its costs too, for preference-map inferences and program projections become more expensive. Still, if complex numerical integrations are necessary to obtain compensated response functions, they need be computed only once, after the functional form issue has been resolved. Finally, Heckman's arguments in favor of his procedure are slightly more persuasive when income tax distortions are introduced into the analysis. However, it remains true that within the received framework the observations are generated by uncompensated structures. Therefore, most of the above applies after average wage rates have been replaced by their appropriate after-tax marginal values.

Let me now turn to the empirical estimates. If nonworking women are to provide information about the structure of preferences, it is necessary to know what market wage opportunities they have foregone. Extrapolations are made from wages of working wives with the same productivity (education and experience) characteristics. Yet there are theoretical reasons for supposing these extrapolations are biased, along the lines of the paper presented by Mincer and Polachek in this volume. Women who have more-permanent labor-force attachments engage in productivity-enhancing activities to a much greater extent than those who have less permanent attachments. 
To put it another way, "Are hours 'caused' by wages, or are wages 'caused' by hours?" Heckman's method assumed an answer of "no" to the second part of this question. But Mincer and Polachek's results suggest the opposite. Women who greatly value market work or who have relatively low home productivities have prior expectations leading them to acquire labor-market skills to a much different degree than women possessing the opposite characteristics. In practice, the result is that estimated market wage opportunities of those out of the labor force tend to be overstated. Estimates of substitution terms in labor-supply equations are biased upward, resulting in upward biased projections of labor-supply responses to child-care programs. Heckman has estimated the model separately for working wives, but the comparisons do not dispose of this point because the statistical treatment of child-care sources is quite different.

My final comment concerns an anomaly in the data. The observations are very thin in the range $0<h<600$, and almost all women who engage in market activities work a significant amount of time during the year. It is problematic how semilog linear reservation wage functions and normally distributed unobserved differences in preferences and market opportunities can account for this gap in the observations. If there is a significant mass of individuals at a boundary solution $(h=0)$ and the distributions are smooth, a nontrivial fraction exhibiting interior solutions close to the boundary is to be expected. This raises some questions regarding sensitivity of the estimates to alternative distributional assumptions. Considering the estimation difficulties associated with normally distributed unobserved "error" components, pursuing other distributions would appear to be infertile ground for future research.

But there is a much simpler explanation for the gap. There may be almost no jobs that offer short work schedules: Market wage opportunities in this range of hours may be nil. The point can be generalized. Most jobs outside the personal service sector offer rather inflexible work schedules (the major exception being volunteer work), with hours-of-work requirements varying from job to job. Insofar as choice of working hours is intermediated by a commensurate choice of job, there is no reason for a single hourly wage to clear all markets for jobs. That is, it may be factually incorrect to assume equality between average and marginal wage rates in the analysis. Wage-hours regressions are not readily interpreted as direct estimates of labor-supply functions in this case. They undoubtedly are related to worker preferences, but contain elements of employer demand and technological considerations as well. It is impossible to say at this point what difference such modifications will make to labor-supply estimates, since a slightly different conceptual framework is required. In any event, this issue seems well worth pursuing. 
In conclusion, Heckman clearly has opened a lot of new territory in the economics of labor supply. The originality of his effort is all the more remarkable when one considers the extent to which the literature shows these grounds have been worked over. Future studies in this area are bound to be affected for many years to come by Heckman's paper. 